\title{
Cardiorespiratory Behavior during Sleep in Full-Term and Preterm Neonates at Comparable Postconceptional Term Ages ${ }^{1}$
}

\author{
MARK S. SCHER, DORIS A. STEPPE, S. GEORGE DOKIANAKIS, MINGUI SUN, \\ ROBERT D. GUTHRIE, AND ROBERT J. SCLABASSI \\ Developmental Neurophysiology Laboratory, Department of Pediatrics, Magee-Womens \\ Hospital, and Departments of Pediatrics and Neurosurgery, Children's Hospital of Pittsburgh, \\ University of Pittsburgh School of Medicine, Pittsburgh, Pennsylvania 15213
}

\begin{abstract}
ABST
Cardiorespiratory behavior during sleep has been inves-
tigated by comparing visually analyzed minutes of EEG tigated by comparing visually analyzed minutes of EEG two physiologic variables for each corresponding minute. Continuous 3-h nighttime sleep studies on 37 full-term and preterm neonates at comparable postconceptional term ages were acquired under controlled conditions, using a 24-channel computerized monitoring system and an automated eventmarker program. Five thousand, two hundred ninety-four minutes were assigned an EEG state by traditional criteria. Eighteen preterm infants were compared with 19 full-term infants with respect to six cardiac and six respiratory measures: two nonspectral calculations (i.e. average per minute and variance of the means) and four spectral calculations of the cardiorespiratory signal (i.e. bandwidth, spectral edge, mean frequency, and ratio of harmonics). The relative capabilities of these measures to predict a sleep state change were investigated using discriminant analysis. A stepwise selection algorithm in discriminant analysis was used to identify the order of significance for the remaining variables. Eight cardiorespiratory measures were then submitted to multivariate analysis of variance to assess sleep state or preterm-full-term differences: mean frequency, bandwidth, average per minute, and ratio of harmonics for cardiac signals; and spectral edge, mean
\end{abstract}

frequency, logarithm of variance, and ratio of harmonics for respiratory signals. Differences among the sleep states and between neonatal groups were highly significant $(p<$ 0.0001 ). Interaction between sleep state and neonatal group was also significant $(p<0.034)$. Two variables differentiated preterm from full-term respiratory behavior: ratio $(p$ $\leq 0.001)$ and mean frequency $(p \leq 0.02)$. Three variables demonstrated differences between preterm and full-term cardiac behavior: average heart rate per minute $(p \leq$ $0.001)$, ratio $(p \leq 0.05)$, and bandwidth $(p \leq 0.08)$. Notably, the lowest values for most spectral measures were noted during tracé alternant quiet sleep compared with the three other segments of the ultradian sleep cycle. Our findings demonstrate sleep state-specific differences in cardiorespiratory behavior in neonates regardless of prematurity. Differences between preterm and full-term infants reflect altered functional development of the brain because of adaptation to prematurity, an extrauterine experience, or both and may contribute to a model of physiologic vulnerability of certain infants for sudden infant death syndrome. (Pediatr Res 36: 738-744, 1994)
Abbreviations
SIDS, sudden infant death syndrome

EEG sleep organization, in general, is comparable for all newborns at postconceptional term ages regardless of prematurity at birth $(1,2)$. However, differences also

Received April 16, 1993; accepted May 18, 1994.

Correspondence and reprint requests: Mark S. Scher, M.D., Developmental Neurophysiology Laboratory, Magee-Womens Hospital, 300 Halket St., Pittsburgh, PA 15213.

Supported in part by Grants NS01110, NS26793, and MO1RR00084 to Dr. Mark S. Scher, the Twenty-Five Club of Magee-Womens Hospital, the Scaife Family Foundation, the Cradle Roll Auxillary of Magee-Womens Hospital, and the Magee-Womens Hospital Research Fund.

${ }^{1}$ Presented in part at the Association of Professional Sleep Societies, Phoenix, AZ, May 1992. have been described between full-term and preterm infants in cardiorespiratory behavior, rapid eye movements, spectral content, and state organization (3-11).

We have reported differences between full-term and preterm infants at matched postconceptional term ages with respect to sleep architecture, continuity, phasic, spectral, and rectal temperature measures (9-11). The two aims of our present study were to investigate cardiorespiratory behavior in neonates during sleep and compare these physiologic measures between full-term and preterm groups of healthy infants who were subsequently normal on neurodevelopmental assessments. 


\section{METHODS}

Patient population. Nineteen full-term and 18 preterm at ostconceptional term age infants were studied (Table 1). Preterm infants had an average gestational age at birth of 28.98 wk but comparable postconceptional term ages and body weights at the time of the EEG sleep recordings.

Healthy preterm neonates of $\leq 32 \mathrm{wk}$ gestational age were prospectively selected from an inborn population at a large obstetrical hospital. Selection criteria were strict, excluding infants with major illnesses. No infants required ventilatory care or suffered intracranial hemorrhage, sepsis, or other major organ system disorders. Monthly EEG sleep studies were obtained on the preterm group until postconceptional term ages.

The last EEG sleep records of the preterm group were compared with EEG studies for a group of full-term neonates at comparable postconceptional term ages. Records for each full-term infant were obtained between 2 and $3 \mathrm{~d}$ of age.

All 37 subjects were examined by at least 18 mo of life and were judged to be healthy and appropriate for neurodevelopmental milestones. Thirty-one subjects were available for the following psychometric evaluations: Bayley Motor and Mental Performance Scales, Carey Temperament Scales, and Vineland Social Maturity Scales. The remaining six were healthy and age appropriate by parental or physician report.

EEG sleep recording sessions. Paper and computer recordings of EEG sleep studies were collected and analyzed using the protocol listed in Figure 1. A 24-channel study was recorded for each infant on a computer workstation (Apollo computers, Hewlett-Packard, Inc., Palo Alto, CA). The initial $3 \mathrm{~h}$ of a 12 -h nighttime study were simultaneously recorded on paper using a Nihon-Kohden model 4221 machine (Irvine, CA) from which a visually scored EEG sleep state was assigned for each minute of the recording. Architectural, phasic, and continuity measures were scored for each minute of sleep. The ultradian neonatal sleep cycle consists of a sequence of state segments that begin and end in active sleep, with two quiet sleep segments occurring between these active sleep segments: mixed frequency active sleep $\rightarrow$ high-voltage slow quiet sleep $\rightarrow$ tracé alternant quiet sleep $\rightarrow$ lowvoltage irregular active sleep $(1,2)$. Minutes of wakefulness and indeterminate sleep were also noted (Fig. 2). Behavioral observations regarding sleep behavior, artifacts, and environmental conditions were also recorded

Table 1. Demographics of neonatal population

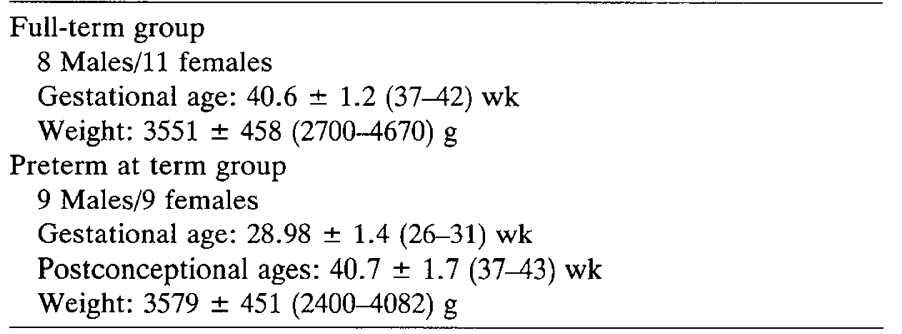

\section{Data Collection and Analysis Protocol}

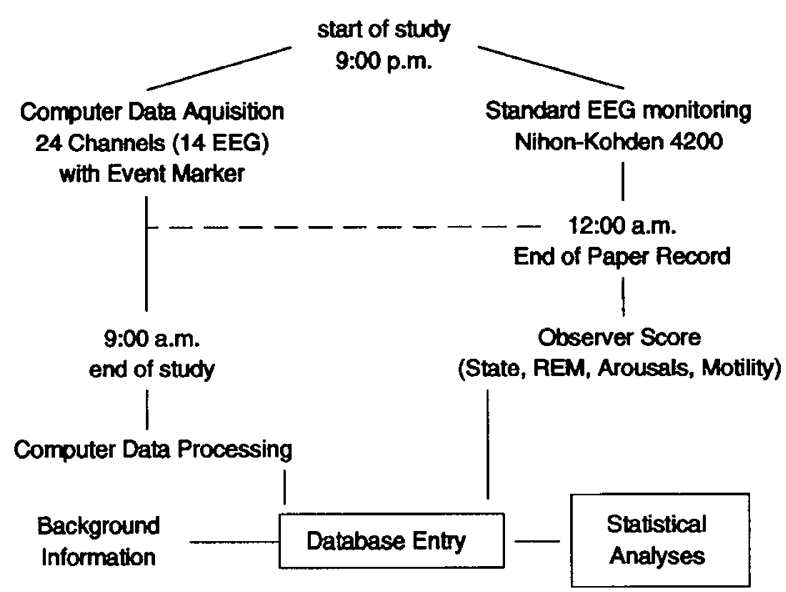

Figure 1. Data collection and analysis protocol. Analyses for this project were obtained from the first $3 \mathrm{~h}$ of the 12 -h recording. $R E M$, rapid eye movements.

on the computer using an event-marker program developed in our laboratory (12). Demographic, clinical, technical, and EEG sleep data were recorded on handwritten data sheets and then entered into a relational database (Borland-Interbase, Inc., Scotts Valley, CA).

Data were acquired with a sampling rate of $64 \mathrm{~Hz}$. Values for each signal (i.e. heart and respiratory calculations, EEG energies) were computed and averaged for every minute. These averages were subsequently entered into our relational database. Minutes during feedings and diaper changes were eliminated. Cardiorespiratory signals were filtered using a five-point median filter. Artifactually induced high and low values were also eliminated. For this particular study, only cardiorespiratory measures were compared between the two study groups based on the visually scored minute of sleep. Continuous measurements of heart rate were collected with a standard ECG electrode on the chest. Respiratory excursions were recorded from the thorax using inductive plethysomography.

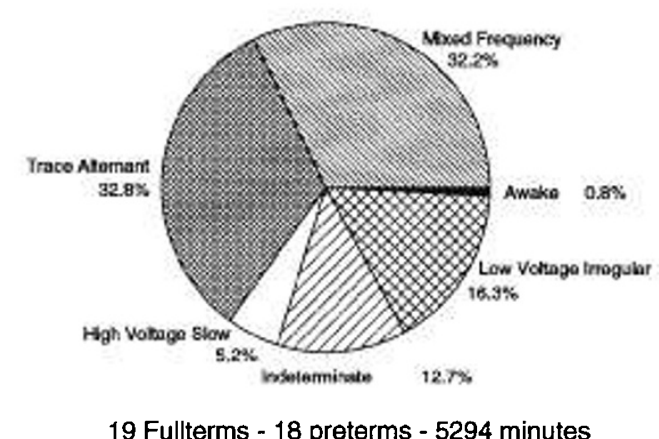

Mixed Frequency $\rightarrow$ High Voltage Slow $\rightarrow$ Trace Alternant $\rightarrow>$ Low Voltage Iregular

Figure 2. Sleep state distribution in our study group. Note the predominance of active sleep (i.e. mixed frequency and low-voltage irregular sleep segments). Quiet sleep segments comprise tracé alternant and high-voltage slow segments. Indeterminate or transitional sleep and waking portions are also listed. 
Data analyses. Computer programs were written to analyze the cardiorespiratory signals. Cardiorespiratory measures can be subdivided into nonspectral and spectral values; two nonspectral measures were average rate and variance of the means. Spectral cardiorespiratory measures consisted of four calculations of the spectral content of the cardiac and respiratory signals: bandwidth, spectral edge, mean frequency, and ratio of harmonic energies. Each of these six measures was averaged over $1 \mathrm{~min}$ and identified with the visually identified EEG sleep for that minute.

Bandwidth calculates the spectral content as measured by the distance between the point at which the spectrum is first greater than $50 \%$ of the maximum of the spectral value and the point at which the spectrum is last less than $50 \%$ of the maximum spectral value. Spectral edge calculates the frequency below which $90 \%$ of the total spectral value is represented. Mean frequency is defined as the center of gravity of the spectrum, and the ratio of harmonics measures the degree of difference between an idealized signal with a sinusoidal pattern and the physiologic signal with which it is compared. Each of these four spectral measures represents either the predominant frequencies contained in the cardiorespiratory signal (i.e. bandwidth, spectral edge, mean frequency) or the regularity of the signal over time (i.e. ratio of harmonics).

Statistical analyses. All analyses were performed using the SAS statistical package (Cary, NC), and the SPSS statistical package (Chicago, IL). Six calculations were applied separately to the raw cardiac signal and six calculations to the respiratory signal. The relative capability of these values to predict sleep-state change was then investigated by stepwise discriminant analysis. The natural logarithmic transformation was used on one variable, the variance of the respiration rate, to achieve a normal distribution. Correlations between pairs of variables did not exceed 0.7. A hierarchical ordering of measures was obtained by the use of a stepwise selection algorithm in discriminant analysis. As a result, the remaining cardiorespiratory measures were submitted to a multivariate analysis of variance using a doubly multivariate repeated measures design.

\section{RESULTS}

Tables 2 and 3 list the mean, SD, and range values for cardiac and respiratory variables. Eight highly significant cardiorespiratory measures were chosen by stepwise discriminant analysis. These included four measures for cardiac signals-mean frequency, bandwidth, ratio of harmonics, and average per minute-and four measures for respiratory signals-spectral edge, mean frequency, variance, and ratio of harmonics.

As a result of multivariate analysis of variance using all data, the difference among the sleep states and the difference between neonatal groups were highly significant $(p<0.0001)$. Interaction between sleep state and neonatal group was also significant $(p<0.034)$.
Two cardiac and one respiratory measure differentiated active from quiet sleep states in all infants, as well as differentiated preterm from full-term cardiorespiratory behavior during these states. Figures 3-7 graphically illustrate the differences between sleep states and between preterm and full-term groups for these selected cardiorespiratory measures (Tables 4-6).

Figure 3 illustrates state-specific changes in average heart rates during active and quiet sleep for all neonates, with lower rates during tracé alternant. Higher average heart rates were noted for preterm infants for all four segments of the neonatal EEG sleep cycle compared with full-term infants. This was the only nonspectral measure that demonstrated differences among states $(p<0.01$, Table 4$)$ as well as between neonatal groups $(p<0.001$, Table 5).

Figure 4 illustrates mean values of the heart rate ratio of harmonics. Differences were noted between active and quiet sleep for all neonates. Lower heart rate ratios were noted for preterm compared with full-term infants during quiet sleep only (Table 5).

Using heart rate bandwidth, differences were noted between active and quiet sleep in all neonates (Fig. 5). A difference between groups was noted during low-voltage irregular sleep state, with higher values for the preterm group (Table 5).

Figure 6 demonstrates differences between active and quiet sleep-state segments for all neonates determined by using respiratory rate ratio of harmonics. The preterm differed from the full-term group, with lower values for the preterm group more prominently noted during both active sleep segments and tracé alternant quiet sleep (Table 5).

Finally, in Figure 7, no sleep state differences in the mean respiratory frequency were noted (Table 4). Differences were noted between full-term and premature infants only during active sleep (Table 5).

Two spectral measures of cardiac behavior, ECG bandwidth and heart rate ratio, demonstrated a significant interaction between sleep state and neonatal group. These persisted when we used only active versus quiet sleep rather than all four states. No respiratory measures demonstrated interaction (Table 6).

\section{DISCUSSION}

We have reported differences in cardiorespiratory behavior between active and quiet sleep in all neonates, as well as between preterm and full-term infant groups at comparable postconceptional term ages. Lower cardiorespiratory values for most measures were noted in the preterm group during tracé alternant quiet sleep than during the other three segments of the sleep cycle.

We previously reported differences between preterm and full-term infants at matched postconceptional term ages with respect to sleep architecture, continuity, phasic, spectral, and temperature measures (9-11). The sleep cycle of the preterm infant at a postconceptional term age 
Table 2. Cardiac variables: means, $S D$, and ranges*

\begin{tabular}{|c|c|c|c|c|c|c|c|}
\hline $\begin{array}{l}\text { Variable, sleep state, } \\
\text { and neonatal group }\end{array}$ & Mean & $\mathrm{SD}$ & Range & $\begin{array}{l}\text { Variable, sleep state, } \\
\text { and neonatal group }\end{array}$ & Mean & $\mathrm{SD}$ & Range \\
\hline Average rate & & & & Bandwidth & & & \\
\hline $\mathrm{M}$ & & & & $\mathrm{M}$ & & & \\
\hline Full & 127.49 & 7.63 & $110.54-136.70$ & Full & 20.03 & 2.11 & $15.98-24.70$ \\
\hline Pre & 148.67 & 5.65 & $137.88-156.85$ & Pre & 21.11 & 1.09 & $19.03-23.23$ \\
\hline LVI & & & & LVI & & & \\
\hline Full & 128.70 & 12.79 & $91.38-152.25$ & Full & 20.18 & 2.03 & $15.62-23.91$ \\
\hline Pre & 148.96 & 7.00 & $137.23-160.51$ & Pre & 21.67 & 1.48 & $19.78-26.00$ \\
\hline HVS & & & & HVS & & & \\
\hline Full & 123.62 & 8.59 & $110.73-142.34$ & Full & 19.62 & 1.91 & $15.65-22.69$ \\
\hline Pre & 147.63 & 6.57 & $138.12-158.15$ & Pre & 20.60 & 1.32 & $18.04-22.76$ \\
\hline TA & & & & TA & & & \\
\hline Full & 122.73 & 9.76 & $112.50-149.69$ & Full & 20.04 & 1.79 & $15.56-22.87$ \\
\hline Pre & 145.97 & 7.15 & $131.81-159.27$ & Pre & 20.25 & 1.30 & $17.56-23.00$ \\
\hline Variance & & & & Ratio of harmonics & & & \\
\hline M & & & & M & & & \\
\hline Full & 3562.09 & 2804.27 & $1077.4-11263.9$ & Full & 0.98 & 0.02 & $0.93-1.00$ \\
\hline Pre & 9907.05 & 13016.08 & $1037.0-43891.0$ & Pre & 0.97 & 0.02 & $0.92-1.00$ \\
\hline LVI & & & & LVI & & & \\
\hline Full & 3551.28 & 2535.88 & $1039.7-11077.9$ & Full & 0.98 & 0.01 & $0.94-1.00$ \\
\hline Pre & 8476.42 & 11826.47 & $1043.5-41953.0$ & Pre & 0.97 & 0.02 & $0.92-1.00$ \\
\hline HVS & & & & HVS & & & \\
\hline Full & 3168.31 & 2126.33 & $939.4-9286.0$ & Full & 0.98 & 0.02 & $0.93-1.00$ \\
\hline Pre & 8080.15 & 11318.02 & $898.1-39730.5$ & Pre & 0.96 & 0.002 & $0.91-1.00$ \\
\hline $\mathrm{TA}$ & & & & $\mathrm{TA}$ & & & \\
\hline Full & 2672.62 & 1434.16 & $849.4-5642.8$ & Full & 0.97 & 0.02 & $0.94-1.00$ \\
\hline Pre & 7704.45 & 10400.35 & $929.8-37606.6$ & Pre & 0.95 & 0.03 & $0.89-1.00$ \\
\hline Mean frequency & & & & Spectral edge & & & \\
\hline M & & & & $\mathrm{M}$ & & & \\
\hline Full & 15.10 & 3.93 & $9.43-20.26$ & Full & 26.43 & 3.14 & $19.59-29.7$ \\
\hline Pre & 15.22 & 3.23 & $9.27-20.44$ & Pre & 27.23 & 1.85 & $23.60-29.8$ \\
\hline LVI & & & & LVI & & & \\
\hline Full & 14.90 & 3.98 & $9.26-20.35$ & Full & 26.44 & 3.03 & $19.18-29.72$ \\
\hline Pre & 15.09 & 3.28 & $9.66-20.47$ & Pre & 27.30 & 1.87 & $23.90-29.91$ \\
\hline HVS & & & & HVS & & & \\
\hline Full & 15.60 & 3.96 & $8.75-20.15$ & Full & 26.67 & 3.19 & $19.38-29.55$ \\
\hline Pre & 15.50 & 3.02 & $8.96-20.55$ & Pre & 27.51 & 1.69 & $23.74-30.04$ \\
\hline $\mathrm{TA}$ & & & & TA & & & \\
\hline Full & 15.80 & 3.35 & $9.64-20.11$ & Full & 27.12 & 2.54 & $19.58-29.65$ \\
\hline Pre & 16.38 & 2.94 & $11.81-21.61$ & Pre & 27.68 & 1.60 & $24.82-30.31$ \\
\hline
\end{tabular}

* Full, full-term; Pre, preterm; M, mixed-frequency active sleep; LVI, low-voltage irregular active sleep; HSV, high-voltage slow quiet sleep; TA, tracé alternant quiet sleep.

is one third longer than for the full-term infant, with a greater percentage of quiet sleep. Preterm neonates have fewer movements, fewer and shorter arousals, higher mean rectal temperatures, and lower spectral EEG energies during specific sleep-state segments than full-term infants. As supported by our present findings, differences in cardiorespiratory behavior also exist between full-term and preterm groups at postconceptional term ages. Differences in these features of sleep organization in preterm neonates may reflect the influences of prematurity, extrauterine experience, or both on brain maturation.

Sleep-state differences in cardiac control have been described for full-term newborns and infants during the first 6 mo of life (13). However, studies of cardiorespiratory behavior in preterm infants are less numerous. In 1988, Aärimaa et al. (14) studied only mean heart rate during quiet sleep. Katona et al. (15) evaluated cardiac behavior for all sleep cycles but only concerning heart rate variability; these authors reported that preterm in- fants displayed higher heart rates than term infants until 7 mo of age. Curzi-Dascalova et al. (16) reported statedependent differences in neonates as young as $31 \mathrm{wk}$ postconceptional age with respect to cardiorespiratory behavior. They also noted that preterm neonates at postconceptional term ages had higher heart rates and lower heart rate variability than full-term neonates; active sleep could be distinguished from quiet sleep by shorter R-R intervals in both high- and low-frequency ranges of heart rate variability. Differences were noted most dramatically between younger and older preterm infants, rather than between near-term and full-term infants. Based on analyses of interbeat intervals, these authors also suggested a steep increase in vagal tone at $37-38$ wk postconceptional age with stability afterward and a more regular increase in sympathetic tone from 31 to $41 \mathrm{wk}$ (17).

Automated spectral techniques mathematically differentiate parasympathetic and sympathetic contributions 
Table 3. Respiration variables: means, SD, and ranges*

\begin{tabular}{|c|c|c|c|c|c|c|c|}
\hline $\begin{array}{l}\text { Variable, sleep state, } \\
\text { and neonatal group }\end{array}$ & Mean & SD & Range & $\begin{array}{l}\text { Variable, sleep state, } \\
\text { and neonatal group }\end{array}$ & Mean & SD & Range \\
\hline Average rate & & & & Spectral edge & & & \\
\hline M & & & & $\mathrm{M}$ & & & \\
\hline Full & 47.38 & 5.72 & $33.56-59.11$ & Full & 1.41 & 0.24 & $1.05-2.12$ \\
\hline Pre & 38.75 & 6.34 & & Pre & 1.21 & 0.16 & $0.90-1.49$ \\
\hline LVI & & & & LVI & & & \\
\hline Full & 46.32 & 7.22 & $32.70-62.12$ & Full & 1.43 & 0.24 & $1.16-2.26$ \\
\hline Pre & 39.09 & 7.27 & $22.29-55.59$ & Pre & 1.23 & 0.15 & $0.91-1.56$ \\
\hline HVS & & & & $\mathrm{HV}$ & & & \\
\hline Full & 48.61 & 8.61 & $35.71-68.85$ & Full & 1.38 & 0.57 & $0.97-3.28$ \\
\hline Pre & 41.76 & 8.17 & $26.85-57.46$ & Pre & 1.26 & 0.51 & $0.62-2.99$ \\
\hline TA & & & & TA & & & \\
\hline Full & 45.67 & 8.73 & $31.91-67.22$ & Full & 1.12 & 0.30 & $0.81-1.93$ \\
\hline Pre & 41.07 & 8.58 & $29.19-61.45$ & Pre & 1.14 & 0.47 & $0.69-2.56$ \\
\hline Mean frequency & & & & Variance & & & \\
\hline M & & & & M & & & \\
\hline Full & 0.86 & 0.14 & $0.62-1.14$ & Full & 288864.2 & 325239.7 & $51319.1-1451398$ \\
\hline Pre & 0.74 & 0.09 & $0.57-0.90$ & Pre & 336720.5 & 260515.4 & $30202.7-1136194$ \\
\hline LVI & & & & LVI & & & \\
\hline Full & 0.86 & 0.13 & $0.67-1.19$ & Full & 298623 & 288908.8 & $56780.0-1292870$ \\
\hline Pre & 0.74 & 0.10 & $0.52-0.99$ & Pre & 321447.7 & 316344.2 & $30535.1-1 \quad 102278$ \\
\hline HVS & & & & HV & & & \\
\hline Full & 0.86 & 0.16 & $0.64-1.16$ & Full & 250788.6 & 306251.2 & $23090.3-1049193$ \\
\hline Pre & 0.79 & 0.15 & $0.41-1.05$ & Pre & 188123.9 & 162313.9 & $29080.7-690359$ \\
\hline TA & & & & TA & & & \\
\hline Full & 0.84 & 0.17 & $0.61-1.23$ & Full & 179022.5 & 241510.5 & $20419.6-1030356$ \\
\hline Pre & 0.79 & 0.14 & $0.60-1.07$ & Pre & 156990.1 & 160133.8 & $25230.7-560335$ \\
\hline Bandwidth & & & & Ratio & & & \\
\hline M & & & & M & & & \\
\hline Full & 1.70 & 0.63 & $1.17-3.49$ & Full & 0.86 & 0.02 & $0.81-0.89$ \\
\hline Pre & 1.60 & 0.52 & $1.01-2.76$ & Pre & 0.81 & 0.03 & $0.77-0.87$ \\
\hline LVI & & & & LVI & & & \\
\hline Full & 1.66 & 0.60 & $1.10-3.32$ & Full & 0.86 & 0.03 & $0.80-0.89$ \\
\hline Pre & 1.56 & 0.47 & $0.95-2.83$ & Pre & 0.82 & 0.04 & $0.77-0.89$ \\
\hline HVS & & & & $\mathrm{HV}$ & & & \\
\hline Full & 1.68 & 0.96 & $0.95-4.59$ & Full & 0.78 & 0.06 & $0.65-0.86$ \\
\hline Pre & 1.80 & 1.34 & $0.87-6.70$ & Pre & 0.74 & 0.08 & $0.53-0.85$ \\
\hline TA & & & & TA & & & \\
\hline Full & 1.68 & 0.92 & $1.69-4.56$ & Full & 0.66 & 0.07 & $0.58-0.83$ \\
\hline Pre & 1.71 & 1.11 & $0.61-5.03$ & Pre & 0.59 & 0.07 & $0.48-0.73$ \\
\hline
\end{tabular}

* Full, full-term; Pre, preterm; M, mixed-frequency active sleep; LIV, low-voltage irregular active sleep; TA, tracé alternant quiet sleep.

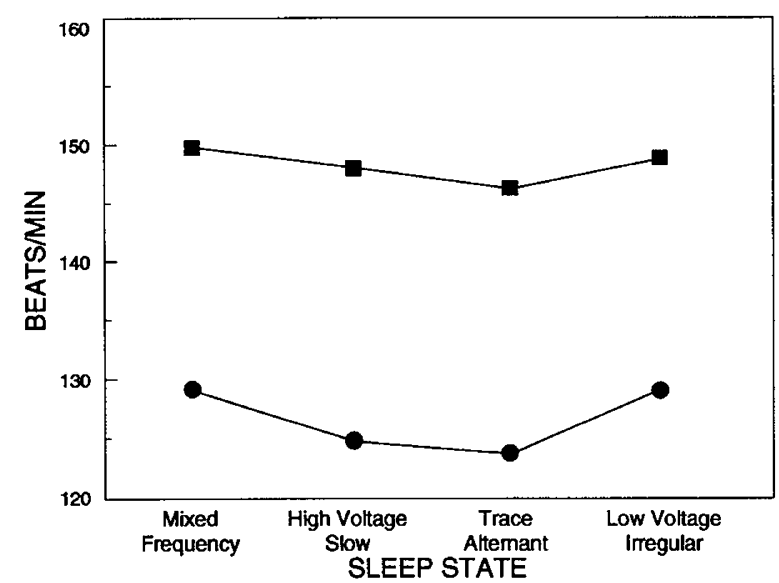

Figure 3. Average heart rate values for study infants comparing preterm and full-term subjects. Higher average heart rates were noted for preterm infants during all stages of sleep.

to cardiac variability (18-20). Automated analyses of digitally acquired cardiorespiratory signals can also help differentiate respiratory and heart rate control by the CNS. Marked effects of breathing patterns on heart rate

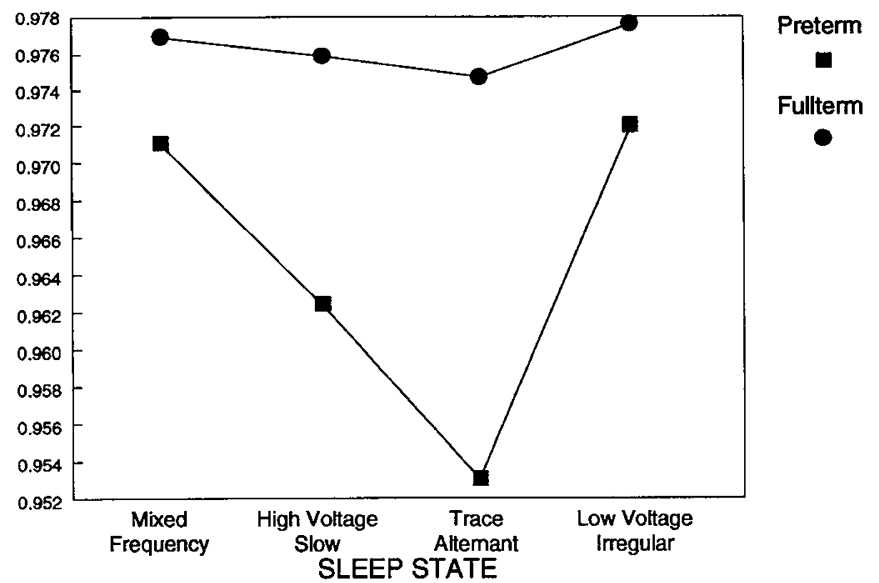

Figure 4. Ratio of harmonics spectral calculation for heart rate are plotted for all subjects, with a lower ratio for the preterm infant most notable during tracé alternant quiet sleep.

and heart rate variability have been described in healthy full-term newborns $(21,22)$. Studies of cardiac interbeat variability not only increase one's understanding of the ontogeny of physiologic responsivity of the autonomic 


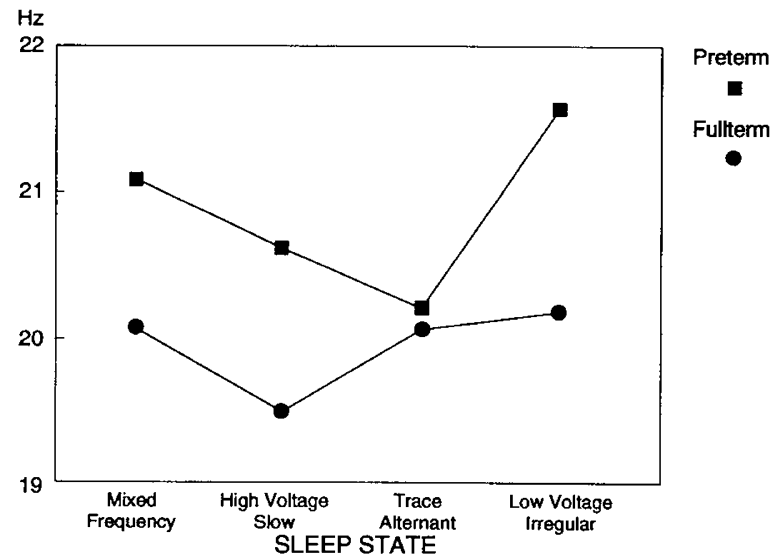

Figure 5. Heart rate bandwidth spectral calculation for study infants, with lower values for term infants during mixed frequency and lowvoltage irregular active sleep segments.

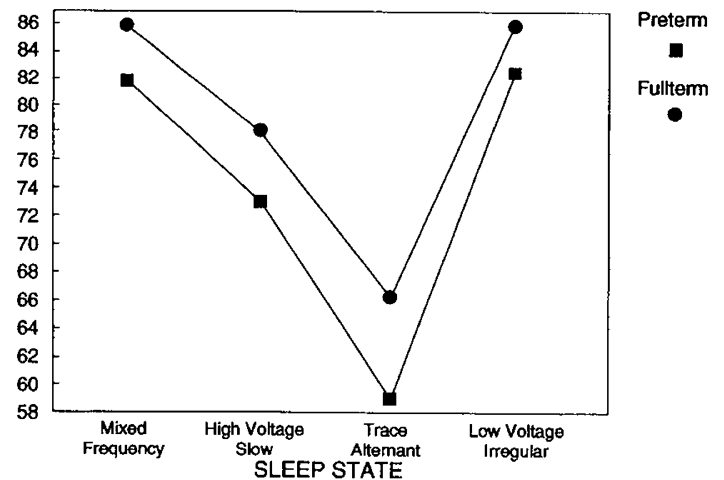

Figure 6. Ratio of harmonics spectral calculation for respiratory rate, with lower values for preterm infants most notable during tracé alternant quiet sleep.

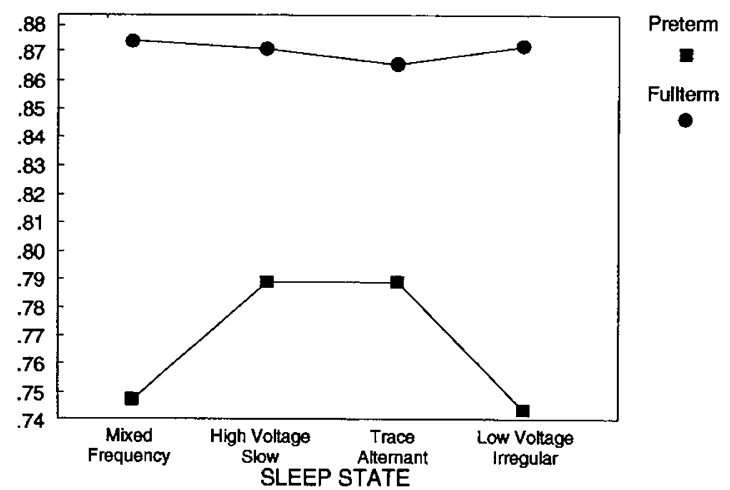

Figure 7. Mean frequency spectral calculation for respiratory rate for study infants, with lower values for preterm infants most notable during active sleep segments.

nervous system as the healthy infant matures $(23,24)$, but also these measures can help identify differences in cardiac function during sleep in infants at risk for SIDS.

Studies of cardiac rate and variation in infants who later died of SIDS have noted higher rates in all states (25) and diminished heart rate variation while awake (24). SIDS victims show reduced dispersion of interbeat intervals across all sleep-waking states with smaller beat-tobeat changes in heart rate relative to controls (26).

Assessment of cardiac parameters must control for sleep state, time of day, relationships with circadian
Table 4. Multivariate analysis of variance results ( $p$ values) for differences among sleep states for cardiorespiratory measures

\begin{tabular}{lcc}
\hline & All four states & Active $v s$ quiet \\
\hline ECG frequency & 0.0008 & 0.0020 \\
ECG bandwidth & 0.0009 & 0.0002 \\
Heart ratio & 0.0001 & 0.0001 \\
Heart average & 0.0252 & 0.0060 \\
Respiration frequency & & \\
Respiration spectral edge & 0.0072 & \\
Respiration ratio & 0.0001 & 0.0001 \\
Log of respiration variance & 0.0001 & 0.0001 \\
\hline
\end{tabular}

Table 5. Multivariate analysis of variance results ( $p$ values) for differences between full-term and premature neonates for cardiorespiratory measures

\begin{tabular}{lccccc}
\hline & $\begin{array}{c}\text { All four } \\
\text { states }\end{array}$ & $\begin{array}{c}\text { Mixed } \\
\text { frequency }\end{array}$ & $\begin{array}{c}\text { High } \\
\text { voltage }\end{array}$ & $\begin{array}{c}\text { Tracé } \\
\text { alternant }\end{array}$ & $\begin{array}{c}\text { Low } \\
\text { voltage }\end{array}$ \\
\hline ECG frequency & & & & & \\
$\begin{array}{l}\text { ECG bandwidth } \\
\text { Heart ratio }\end{array}$ & 0.0398 & & 0.0234 & 0.0039 & 0.0161 \\
$\begin{array}{l}\text { Heart average } \\
\begin{array}{l}\text { Respiratory } \\
\text { frequency }\end{array}\end{array}$ & 0.0001 & 0.0001 & 0.0001 & 0.0001 & 0.0001 \\
$\begin{array}{l}\text { Respiratory } \\
\text { spectral edge }\end{array}$ & & 0.0026 & & & 0.0052 \\
$\begin{array}{l}\text { Respiratory ratio } \\
\text { Log of respiratory } \\
\text { variance }\end{array}$ & 0.0005 & 0.0001 & & 0.0030 & 0.0008 \\
\hline
\end{tabular}

Table 6. Multivariate analysis of variance results ( $p$ values) for interactions between sleep state and full-term or premature infants

\begin{tabular}{lcc}
\hline & All four states & Active $v s$ quiet \\
\hline ECG frequency & & \\
ECG bandwidth & 0.0021 & 0.0260 \\
Heart ratio & 0.0003 & 0.0001 \\
Heart average & & \\
Respiration frequency & & \\
Respiration spectral edge & & \\
Respiration ratio & & \\
Log of respiration variance & & \\
\hline
\end{tabular}

influences on biologic rhythms, and relationships with respiratory parameters (27-30). Digital filtering techniques help identify frequency- and time-dependent relationships among other physiologic signals, such as respirations. One particular measure, respiratory sinus arrhythmia (23), has been used by a number of researchers to demonstrate important changes in cardiorespiratory behavior as the neonate matures during infancy. These studies not only contribute to our understanding of the ontogeny of state-specific cardiorespiratory behavior in normal infants under different state conditions and ages, but also focus on dysfunction of autonomic control in SIDS victims.

The establishment of normative cardiorespiratory behavior in healthy asymptomatic preterm infants as they mature to postconceptional term ages provides useful information regarding alterations in brain maturation in a population at increased risk for SIDS (31). Given the higher mean heart rates and less-organized cardiorespi- 
ratory behavior during quiet sleep in preterm infants, we speculate that preterm neonates at postconceptional term ages may have autonomic behavior similar to that noted for SIDS victims (26), with altered brain function, which potentially affects other vital functions such as cardiorespiration regulation.

We recognize that the minute-by-minute averages of nonspectral and spectral values for cardiorespiratory behavior reported in our study are gross measures of physiologic function and do not delineate dynamic changes in variability that continuously occur $(23,24,26)$. Differences in cardiorespiratory behavior between sleep states as well as between neonatal study groups nonetheless have been demonstrated. These preliminary findings can serve as a basis for comparison with these more sophisticated computer algorithms.

We therefore conclude that specific measures of cardiorespiratory behavior detect sleep-state-specific differences, as well as differences between preterm and fullterm infants at similar postconceptional term ages. How long these differences will persist with maturation during infancy needs to be explored in future analyses.

\section{REFERENCES}

1. Pope SS, Stockard JE, Bickford RG (eds) 1992 Atlas of Neonatal Electroencephalopathy, 2nd Ed. Raven Press, New York

2. Anders T, Einde R, Parmelee A (eds) 1971 A Manual of Standardized Terminology, Technique and Criteria for Scoring States of Sleep and Wakefulness in Newborn Infants. UCLA Brain Information Service/RRI Publications Office, NINDS Neurological Information Network, Los Angeles

3. Dreyfus-Brisac C 1970 Ontogenesis of sleep in human prematures after 32 weeks of conceptional age. Dev Psychobiol 3:91-121

4. Ellingson RJ, Peters JF 1980 Development of EEG and daytime sleep patterns in low risk premature infants during the first year of life: longitudinal observations. Electroencephalogr Clin Neurophysiol 50:165-171

5. Booth CL, Leonard HL, Thoman EB 1980 Sleep states and behavior patterns in preterm and fullterm infants. Neuropediatrics 11:354-364

6. Karch $D$, Rothe R, Jurisch R, Heldt-Hildebrandt R, Lubbesmeier A, Lemburg P 1982 Behavioral changes and bioelectric brain maturation of preterm and full-term newborn infants: a polygraphic study. Dev Med Child Neurol $24: 30-47$

7. Havlicek V, Childiaeva R, Chernick V 1975 EEG frequency spectrum characteristics of sleep states in full-term and preterm infants. Neuropediatrics 6:24- 40

8. Clairambault J, Curzi-Dascalova L, Kauffmann F, Médigue C, Leffler C 1992 Heart rate variability in normal sleeping full-term and preterm neonates. Eariy Hum Dev 28:169-183

9. Scher MS, Sun M, Steppe DA, Guthrie R, Sclabassi R 1991 Extrauterine influence on EEG-sleep in the healthy preterm neonate at term. Ann Neuro 30:488

10. Scher MS, Steppe DA, Dahl RE, Asthana S, Guthrie RD 1992 Comparison of EEG-sleep measures in healthy fullterm and preterm infants at matched conceptional ages. Sleep 15:442-448
11. Scher MS, Dokianakis SG, Sun M, Steppe DA, Guthrie RD, Sclabassi RJ 1992 Differences in thermoregulatory control during sleep between fullterm and preterm neonates at matched postconceptional ages. Sleep Res 21:95

12. Scher MS, Sun M, Hatzilabrou G, Greenberg NL, Cebulka G, Krieger D, Guthrie RD, Sclabassi RJ 1990 Computer analyses of EEG-sleep in the neonate: methodological considerations. J Clin Neurophysiol 7:417-441

13. Schechtman VL, Harper RM, Kluge KA 1989 Development of heart rate variation over the first six months of life in normal infants. Pediatr Res 26:343-346

14. Äärimaa T, Oja R, Antila K, Välimäki I 1988 Interaction of heart rate and respiration in newborn babies. Pediatr Res 24:745-750

15. Katona PG, Fransz A, Egbergt J 1980 Maturation of cardiac control in fulterm and preterm infants during sleep. Early Hum Dev 41:145-159

16. Curzi-Dascalova L, Clairambault J, Kauffmann F, Médigue C, Peirano 1991 Cardiorespiratory variability and development of sleep state organization. In: Gaultier C, Escourrou P, Curzi-Dascalova L (eds) Sleep and Cardiorespiratory Control. John Libbey, London, pp 155-163

17. Clairambault J, Curzi-Dascalova L, Kauffmann F, Médigue C, Leffler C 1992 Heart rate variability in normal sleeping full-term and preterm neonates. Early Hum Dev 28:169-183

18. Akselrod S, Gordon D, Madwed J, Snidman N, Shannon D, Cohen J 1985 Hemodynamic regulation: investigation by spectral analysis. Am J Physio 249:H867-H875

19. Kitney R 1984 New findings in the analysis of heart rate variability in infants. Automed 5:289 310

20. Randall DC, Brown DR, Raisch RM, Yingling JD, Randall WC 1991 SA nodal parasympathectomy delineates autonomic control of heart rate power spectrum. Am J Physiol 260:H985-H988

21. Hathorn MKS 1987 Respiratory sinus arrhythmia in newborn infants. J Physiol 385:1-12

22. Rother M, Zwiener U, Eiselt M, Witte H, Zwacka G, Frenzel J 1987 Differentiation of healthy newborns and newborns-at-risk by spectral analysis of heart rate fluctuations and respiratory movements. Early Hum Dev 15:349 363

23. Kluge KA, Harper RM, Schechtman VL, Wilson AJ, Hoffman HJ, Southall DP 1988 Spectral analysis assessment of respiratory sinus arrhythmia in normal infants and infants who subsequently died of sudden infant death syndrome. Pediatr Res 24:677-682

24. Schechtman VL, Harper RM, Kluge KA, Wilson AJ, Hoffman HJ, Southall DP 1989 Heart rate variation in normal infants and victims of sudden infant death syndrome. Early Hum Dev 19:167-181

25. Wilson AJ, Stevens V, Franks CI, Alexander J, Southall DP 1985 Respiratory and heart rate patterns in infants destined to be victims of the sudden infant death syndrome: average rates and their variability measured over 24 hours. BMJ 290:497-501

26. Schechtman VL, Raets SL, Harper RK, Garfinkel A, Wilson AJ, Southall DP, Harper RM 1992 Dynamic analysis of cardiac R-R intervals in normal infants and in infants who subsequently succumbed to the sudden infant death syndrome. Pediatr Res 31:606-612

27. Schechtman VL, Harper RM 1992 The maturation of correlations between cardiac and respiratory measures across sleep states in normal infants. Sleep $15: 41-47$

28. Schechtman VL, Harper RM 1991 Time of night effects on heart rate variation in normal neonates. J Dev Physiol 16:349-353

29. Schechtman VL, Harper RM, Wilson AJ, Southall DP 1991 Sleep apnea in infants who succumb to the sudden infant death syndrome. Pediatrics 87:841846

30. Harper R, Frostig Z, Taube D, Hoppenbrouwers T, Hodgman J 1983 Development of sleep-waking temporal sequencing in infants at risk for the sudden infant death syndrome. Exp Neurol 79:821-829

31. Hoffmann H, Damas K, Hillman J, Krongrad E 1988 Risk factors for SIDS Results of the National Institute of Child Health and Human Developmen SIDS Cooperative Epidemiological Study. Ann NY Acad Sci 533:13-30 